\title{
Studies on Morphology, Growth Behavior and Seed Production Capacity of Different Species of Weedy Rice under Red and Lateritic Belt of West Bengal, India
}

\author{
Anupam Mukherjee ${ }^{1 *}$ and Buddhadeb Duary ${ }^{2}$ \\ ${ }^{1}$ Sasya Shyamala Krishi Vigyan Kendra, Ramakrishna Mission Vivekananda Educational and \\ Research Institute (RKMVERI), Arapanch, Sonarpur, Kolkata-700150, West Bengal, India \\ ${ }^{2}$ Department of Agronomy, Institute of Agriculture, Visva-Bharati, Sriniketan, \\ West Bengal, India \\ *Corresponding author
}

\section{A B S T R A C T}

\section{Keywords}

Height,

Morphology, Seed weight, Tillers, Weedy rice species

Article Info

Accepted:

18 August 2020

Available Online:

10 September 2020
The experiment was laid out in a randomized block design with five replications in earthen pots with four different weedy rice genotypes viz. $O$. rufipogon, O. nivara, $O$. barthii and $O$. minuta. Data were subjected to analysis of variance using MS-Excel worksheet. Different morphological and growth behaviors characters and yield parameters were recorded for the morphological study of the different species. The highest plant height was observed in Oryza rufipogon which was statistically at par with $O$. barthii and $O$. nivara, whereas $O$. minuta registered the lowest. The lowest number of tillers plant ${ }^{-1}$ at maturity was recorded by Oryza rufipogon. The highest number of tillers at maturity was registered by $O$. nivara which was statistically at par with $O$. minuta. The highest number of panicles plant ${ }^{-1}$ at maturity of weedy rice was recorded by the species $O$. nivara. The lowest number of panicles plant ${ }^{-1}$ recorded from the species Oryza rufipogon. The species $O$. minuta registered the highest number of seeds plant ${ }^{-1}$ which was statistically at par with $O$. nivara. The lowest number of seeds plant ${ }^{-1}$ was recorded by the species $O$. rufipogon. Among the weedy rice species $O$. rufipogon registered the lowest 1000 seed weight whereas $O$. minuta recorded the highest one.

\section{Introduction}

Weedy rice (red rice), a conspecific weed of cultivated rice (Oryza sativa L.), is a significant problem throughout the world and an emerging threat in many Asian regions. Weedy rice, a weedy form of cultivated rice crossed with wild rice competes aggressively with the crop, reducing yields and contaminating harvests. It has been identified 
as one of the most problematic weeds in the 21 st century which seriously affects rice yields. Weedy rice is now affecting rice areas of various countries in Asia, including India, Malaysia, Sri Lanka, Philippines, Thailand, Viet Nam, and South Korea. With diverse biotype, weedy rice has already spread and infested in more than 50 countries in Asia, Africa and Latin America. In India, weedy rice infestations are seen in West Bengal, Andhra Pradesh, Assam, Bihar, Karnataka, Madhya Pradesh, Orissa, Tamil Nadu and Uttar Pradesh (Abraham and Jose, 2015). It is known by different names in different countries. Examples are "Padi Angin" in Malaysia, "Lua Lon" in Vietnam, "Lutao" in China, "Akamai" in Japan, "Sharei" in Korea, "Khao Pa" in Laos, "Khao Nok" in Thailand and "Jhora Dhan" in Bangladesh and West Bengal. Heavy infestation of weedy rice in rice fields of many countries including some of the states in India (eastern U.P., Bihar, Orissa, Manipur and West Bengal and southern India) during recent years is forcing farmers to abandon the crop due to huge reduction in crop yield around 30-60 percent depending on the severity of infestation (AICRP-WC, 2010). Variations in plant height, tiller production, pigmentation, length of awn and grain are noticed in the wild and weedy rice types of India. Heavy infestation of weedy rice ecotypes in rice fields is a problem in eastern India (Weedy rice is a superior competitor to crop cultivars due to its early vigour, greater tillering and height of plants. Early shattering of seeds, variable seed dormancy, high seed persistence in soil and high nitrogen use efficiency make this weed a strong invader. Growth and competitive ability of weedy rice may vary considerably due to differences in plant height, tiller and leaf area producing capacity (Estorninos et al., 2002). Unlike cultivated varieties, weedy rice seeds show variable degree of dormancy and tendency for the seeds to shatter as soon as they are matured (Perreto et al., 1993).
Seeds mature within a short period and shatter immediately facilitating the build-up of weed seed bank before the farmer gets a chance to remove the seeds and got along with the harvest of rice crop. Emergence of weedy rice is greatly influenced by the soil texture, presence of water in the field and the depth of seed burial, which in turn is strictly related to the tillage adopted for seedbed preparation. The minimum temperature for weedy rice germination is considered to be $10^{\circ} \mathrm{C}$, same as that of cultivated rice.

Since the extent and nature of damage depend upon the types of weed, their intensity of infestation, the association with the crop and other biotic and edaphic characteristics, proper knowledge on composition of weed flora in the field crop of a specific region along with their identification, characterization, and assessment are necessary to formulate an economic and effective weed management strategy. Therefore, it is essential to make a information bank on weed biology and ecology is extremely important to prepare better strategy for effective management of the species (Duary et al., 2015). The speedy spread of weedy rice in India serves as a warning to rice-growing states. Immediate attention is to be given towards investigating the weedy rice infestation in India, its biology and management. Integrated and diversified strategies for management of weedy rice should be urgently developed for sustainable rice production under the changing situation of global warming, high labour costs, increased adoption of alternative crop establishment methods and water scarcity.

With these perspectives the investigation on "Studies on morphology, growth behavior and seed production capacity of different species of weedy rice under red and lateritic belt of West Bengal" was carried out. 


\section{Materials and Methods}

Before the experiment conducted a survey was done to find weedy rice species from the survey area i.e. the red and lateritic belt of West Bengal. Red and Lateritic belt of west Bengal consist of Purulia, Bankura, Birbhum and parts of Burdwan district of West Bengal. The experiment was carried out during 2014'15 at Sriniketan, Birbhum district of West Bengal. The experiment was laid out in a randomized block design with five replications in earthen pots.

The four different weedy rice genotypes viz. $O$. rufipogon, $O$. nivara, $O$. barthii and $O$. minuta were taken as treatments. MTU 7027 of paddy plants were simultaneously grown in pots for comparisons.

Data were taken in every 5-7 days interval to noticed any characteristic change in behavior of weedy rice species. Data were subjected to analysis of variance (ANOVA) using MSExcel worksheet. Plant height at maturity, culm length, Leaf length and width, ligule length, panicle length, spikelet, colour of spikelet, colour of nodes and internodes, awn length, awn colour, apiculas colour, stigma colour, 1000 grain weight (g), grain length and width $(\mathrm{mm})$ were recorded for the morphological study of the different species of weedy rice.

\section{Results and Discussion}

The morphological characters of four weedy rice species i.e. Oryza rufipogon, $O$. barthii, $O$. minuta and $O$. nivara are presented in the Table 1. It revealed that Oryza rufipogon, $O$ barthii and $O$. nivara registered plant height taller than cultivated rice at maturity except $O$. minuta which was as tall as cultivated rice variety MTU 7029 (Fig. 1). Details and other morphological studies have been presented in Table 1 and described below:

\section{Plant height (cm)}

The data on plant height $(\mathrm{cm})$ at maturity of weedy rice species were statistically analysed and presented in Table 2. From the Table it revealed that the highest plant height was observed in Oryza rufipogon species which was statistically at par with $O$. barthii and $O$. nivara. The lowest plant height was observed in O. minuta.

\section{Number of tillers plant ${ }^{-1}$ at maturity}

The data on number of tillers plant ${ }^{-1}$ at maturity of weedy rice species as presented in Table 2 revealed that the lowest number of tillers plant ${ }^{-1}$ at maturity was recorded by Oryza rufipogon. The highest number of tillers at maturity was registered by $O$. nivara which was statistically at par with $O$. minuta and $O$. barthii.

\section{Number of panicles plant ${ }^{-1}$ at maturity}

The highest number of panicles plant ${ }^{-1}$ at maturity of weedy rice was recorded by the species $O$. nivara which was statistically at par with the species $O$. minuta. The lowest number of panicles plant ${ }^{-1}$ recorded from the species Oryza rufipogon (Table 2).

\section{Number of seeds plant ${ }^{-1}$}

The Table expressed that the species $O$. minuta registered the highest number of seeds plant $^{-1}$ which was statistically at par with $O$. nivara and $O$. barthii. The lowest number of seeds plant was recorded by the species $O$. rufipogon.

\section{Number of filled grains plant ${ }^{-1}$}

O. minuta registered the highest number of filled grains plant ${ }^{-1}$. The lowest number of filled grains plant ${ }^{-1}$ was recorded by the species $O$. rufipogon (Table 2). 
Table.1 Morphological characters of four weedy rice species

\begin{tabular}{|c|c|c|c|c|}
\hline \multirow[t]{2}{*}{ Characters } & \multicolumn{4}{|c|}{ Species } \\
\hline & Oryza rufipogon & Oryza barthii & Oryza minuta & Oryza nivara \\
\hline Plant & $\begin{array}{l}\text { Taller } \\
\text { cultivated rice }\end{array}$ & $\begin{array}{l}\text { Taller } \\
\text { cultivated rice }\end{array}$ & $\begin{array}{l}\text { As tall as } \\
\text { cultivated rice }\end{array}$ & $\begin{array}{l}\text { Taller than } \\
\text { cultivated rice }\end{array}$ \\
\hline Culm & Thin, very slender & Thick, strong & Thin, very slender & Thick, strong \\
\hline Leaf & $\begin{array}{l}\text { Length : } 19.5 \mathrm{~cm} \\
\text { Width: } 0.75 \mathrm{~cm}\end{array}$ & $\begin{array}{l}\text { Length : } 28.5 \mathrm{~cm} \\
\text { Width: } 0.80 \mathrm{~cm}\end{array}$ & $\begin{array}{l}\text { Length : } 21.5 \mathrm{~cm} \\
\text { Width: } 0.75 \mathrm{~cm}\end{array}$ & $\begin{array}{l}\text { Length : } 25.0 \mathrm{~cm} \\
\text { Width: } 0.85 \mathrm{~cm}\end{array}$ \\
\hline Ligule & $\begin{array}{l}1.05 \mathrm{~cm} \text { long, } \\
\text { narrowly triangular }\end{array}$ & $\begin{array}{l}2.35 \mathrm{~cm}, \quad \text { very } \\
\text { narrowly triangular }\end{array}$ & $\begin{array}{l}0.85 \mathrm{~cm} \text { long, } \\
\text { triangular }\end{array}$ & $\begin{array}{l}1.5 \quad \mathrm{~cm} \text { long } \\
\text { triangular }\end{array}$ \\
\hline Panicle & $\begin{array}{l}30 \mathrm{~cm} \text { long, lax, } \\
\text { branches right } \\
\text { angle to rachis, }\end{array}$ & $\begin{array}{l}24 \quad \mathrm{~cm} \text { long, } \\
\text { compact, branches } \\
\text { ascending and close } \\
\text { to rachis }\end{array}$ & $\begin{array}{l}17.5 \mathrm{~cm} \text { long, } \\
\text { compact, branches } \\
\text { ascending and } \\
\text { close to rachis }\end{array}$ & $\begin{array}{l}20.5 \quad \mathrm{~cm} \text { long, } \\
\text { compact, branches } \\
\text { ascending and } \\
\text { close to rachis }\end{array}$ \\
\hline Spikelet & $\begin{array}{l}\text { Filled grain } 65 \% \text {, } \\
\text { greenish-yellow } \\
\text { with deep pinkish- } \\
\text { red awn }\end{array}$ & $\begin{array}{l}\text { Filled grain } 84 \%, \\
\text { yellow with deep } \\
\text { pinkish-red awn }\end{array}$ & $\begin{array}{l}\text { Filled grain } 91 \% \text {, } \\
\text { black with black } \\
\text { awn }\end{array}$ & $\begin{array}{l}\text { Filled grain } 86 \% \text {, } \\
\text { yellow turning to } \\
\text { brown with white } \\
\text { awn }\end{array}$ \\
\hline Colour of nodes & Green & Green & Green & Green \\
\hline Internodes colour & Purple green & Green & Blackish green & Pinkish green \\
\hline Awn & Long awned & Long awned & Very short awned & Long awned \\
\hline Awn colour & Red & Red & Black & Red \\
\hline Apiculas colour & Red & Red & Black & Red \\
\hline Stigma colour & Purple & Purple & Blackish purple & Purple \\
\hline 1000 grain weight (g) & 11.9 & 21.3 & 23.5 & 20.2 \\
\hline Grain length & $6.10 \mathrm{~mm}$ & $6.40 \mathrm{~mm}$ & $6.10 \mathrm{~mm}$ & $6.30 \mathrm{~mm}$ \\
\hline Grain width & $1.60 \mathrm{~mm}$ & $2.35 \mathrm{~mm}$ & $1.75 \mathrm{~mm}$ & $2.30 \mathrm{~mm}$ \\
\hline
\end{tabular}

Table.2 Morphological characters of four weedy rice species

\begin{tabular}{|c|c|c|c|c|c|c|}
\hline \multirow[t]{2}{*}{ Species } & \multicolumn{6}{|c|}{ Parameters } \\
\hline & $\begin{array}{l}\text { Plant } \\
\text { Height }(\mathbf{c m}) \\
\text { at maturity }\end{array}$ & $\begin{array}{l}\text { No. of tillers } \\
\text { plant }^{-1} \text { at } \\
\text { maturity }\end{array}$ & $\begin{array}{l}\text { No. of } \\
\text { panicles } \\
\text { plant }^{-1} \text { at } \\
\text { maturity }\end{array}$ & $\begin{array}{l}\text { No. of } \\
\text { seeds } \\
\text { plant }^{-1}\end{array}$ & $\begin{array}{l}\text { No. of } \\
\text { fertile } \\
\text { grains } \\
\text { plant }^{-1}\end{array}$ & $\begin{array}{l}1000 \text { seed } \\
\text { weight } \\
\text { (g) }\end{array}$ \\
\hline Oryza rufipogon & 138.1 & 11.4 & 9.0 & 810.8 & 526.2 & 11.90 \\
\hline Oryza barthii & 129.9 & 23.6 & 16.2 & 1268.0 & 1062.8 & 21.30 \\
\hline Oryza minuta & 104.7 & 26.8 & 22.4 & 1901.2 & 1730.0 & 23.50 \\
\hline Oryza nivara & 128.4 & 28.2 & 26.8 & 1706.8 & 1480.4 & 20.20 \\
\hline S. Em \pm & 8.7 & 1.8 & 1.9 & 122.7 & 71.4 & 0.54 \\
\hline CD (at 0.05) & 26.9 & 5.7 & 5.8 & 378.2 & 220.0 & 1.73 \\
\hline CV $(\%)$ & 12.59 & 11.30 & 12.73 & 19.31 & 10.54 & 11.39 \\
\hline
\end{tabular}


Figure.1 Different morphological characters of four weedy rice species
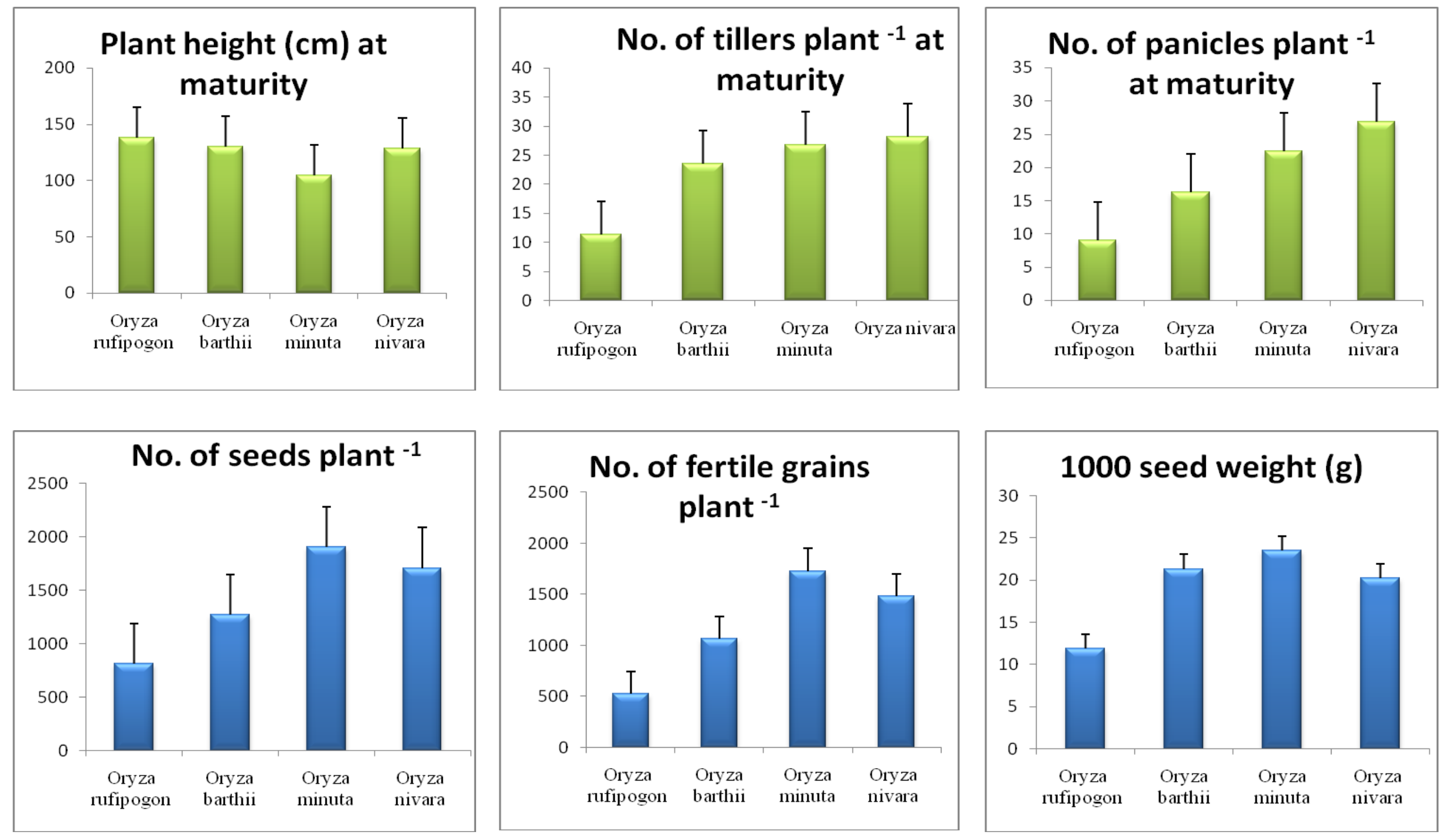


\section{0 seed weight $(g)$}

The data on 1000 seed weight of weedy rice were statistically analysed and presented in Table 2. From the Table it expressed that among the weedy rice species $O$. rufipogon registered the lowest 1000 seed weight. On the other hand the highest 1000 seed weight was recorded by the species $O$. minuta followed by $O$. barthii and $O$. nivara.

The results revealed that the Oryza rufipogon, $O$ barthii and $O$. nivara registered plant height taller than cultivated rice at maturity except $O$. minuta which was as tall as cultivated rice variety MTU 7029. Same findings were observed by Park et al., (1999), Baki et al., (1999), Baki et al., (2000), Yu et al., (2005) and Shivrain et al., (2010). The lowest numbers of tillers plant ${ }^{-1}$ at maturity was recorded by Oryza rufipogon. The highest number of tillers at maturity was registered by $O$. nivara which was statistically at par with O. minuta and O. barthii (Table 2). The highest number of panicles plant ${ }^{-1}$ at maturity of weedy rice was recorded by the species $O$. nivara which was statistically at par with the species $O$. minuta.

The lowest number of panicles plant $^{-1}$ recorded from the species Oryza rufipogon. The Table 2 expressed that the species $O$. minuta registered the highest number of seeds plant $^{-1}$ which was statistically at par with $O$. nivara and $O$. barthii. The lowest number of seeds plant was recorded by the species $O$. rufipogon. O. minuta registered the highest data on number of fertile grains plant $^{-1}$ presented in the Table 2. The lowest number of fertile grains plant ${ }^{-1}$ was recorded by the species $O$. rufipogon. Among the weedy rice species $O$. rufipogon registered the lowest 1000 seed weight. On the other hand the highest 1000 seed weight was recorded by the species $O$. minuta followed by $O$. barthii and $O$. nivara. The expression of vegetative and reproductive characters is mainly regulated by genetic behavior of a species, though environment plays an important role. Different weedy rice species under the present investigation expressed their vegetative and reproductive characters and which varied significantly among the species. Though weedy rice species $O$. rufipogon is very frequently observed in low lying waterlogged areas by the side of the road and the adjacent to rice field but the tiller production, panicle plant $^{-1}$, seeds panicle ${ }^{-1}$, and 100 seed weight were the lowest which were also recorded in the present investigation. Similar reports of lower values of reproductive parameters were earlier reported by Baki et al., (2000). On the other hand $O$. minuta and $O$. nivara produced higher number of tillers hill ${ }^{-1}$, panicles hill ${ }^{-1}$, seeds panicle ${ }^{-1}$ and also higher test weight. The results were in congruity with Chin (1997), Chin et al., (2000) and Baki et al., (2000).

Conclusion is as follows:

While studying biology of weedy rice species the highest plant height was observed in Oryza rufipogon which was statistically at par with $O$. barthii and $O$. nivara. The lowest plant height was observed in O. minuta. But the lowest number of tillers plant ${ }^{-1}$ at maturity was noticed in Oryza rufipogon whereas it was the highest in $O$. nivara which was statistically at par with $O$. minuta and $O$. barthii. The lowest number of panicles plant ${ }^{-1}$ was also recorded in the species Oryza rufipogon. O. minuta registered the highest number of seeds plant ${ }^{-1}$ and filled grains plant ${ }^{-}$ ${ }^{1}$ which was statistically at par with $O$. nivara and $O$. barthii. The species $O$. rufipogon also registered the lowest number of seeds plant ${ }^{-1}$ and 1000 seed weight. On the other hand the highest 1000 seed weight was recorded by the species $O$. minuta followed by $O$. barthii and $O$. nivara. 


\section{References}

Abraham, C. T. and Jose, N. (2015). Weedy rice invasion and its management. Indian Journal of Weed Science 47(3): 216-223.

AICRP -WC, (2010). Twenty fifth Annual Progress Report of All India Coordinated Research programme on Weed Control, Visva Bharati, Sriniketan Centre, Visva Bharati.

Baki, B. B., Chin, D. V. and Motimer, M. (2000). Wild and Weedy Rice in Rice Eco-sytems in Asis- a Review. Limited Proceedings, IRRI.

Baki, B. B., Dayot, M., Boyce, A. N. and Jaafar, A. M. (1999). Allometric response and growth patterns of three accessions of weedy rice and a cultivated rice (Oryza sativa L. cv. MR84) in Malaysia. Journal of Weed Science and Technology 44(2): 115124.

Chin, D. V., Hien, T. V. and Thiet, L. V. (2000). Weedy rice in Vietnam. In: Wild and Weedy Rice in Rice Ecosystems in Asia- A review (Eds. Baki BB, Chin DV and Mortimer M). IRRI, Manila.

Chin, D.V. (1997). Occurrence of weedy rice in Vietnam. In: Proceedings of the 16th Asian-Pacific Weed Science Society
Conference (Kuala Lumpur, Malaysia, 8-12 September 1997). Asian-Pacific Weed Science Society, Kuala Lumpur. pp. 243-245.

Duary, B., Mishra, M. M., Dash, R. and Teja, K. Charan. (2015). Weed management in lowland rice in India. Indian Journal of Weed Science 47(3): 224-232.

Estorninos, L. E., Gealy, D. R. Jr. and Talbert, R. E. (2002). Growth response of rice (Oryza sativa) and red rice (O. sativa) in a replacement series study. Weed Technology 16: 401-406.

Perreto, E. L., Peske, S. T. and Galli, J. (1993). Evaluation of weedy rice seeds and plants. Revista Brasileira de Sementes 15(1): 49-54.

Shivrain, V. K., Burgos, N. R., Scott, R. C., Gbur, E. E. Jr., Estorninos, L. E. Jr. and McClelland, M. R. (2010). Diversity of weedy red rice (Oryza sativa L.) in Arkansas, U.S.A. in relation to weed management. Crop Protection. 29(7): 721-730.

Yu, L., Johnson, D. E., Zhou, Y. J., Zhang, J. P. and Xuan, S. N. (2005). The biological characteristics and control of a weedy rice Luolijing (Oryza sativa). Acta Phytophylacica Sinica. 32(3): 319323.

\section{How to cite this article:}

Anupam Mukherjee and Buddhadeb Duary. 2020. Studies on Morphology, Growth Behavior and Seed Production Capacity of Different Species of Weedy Rice under Red and Lateritic Belt of West Bengal, India. Int.J.Curr.Microbiol.App.Sci. 9(09): 2665-2671.

doi: https://doi.org/10.20546/ijcmas.2020.909.332 